\title{
DESENVOLVIMENTO E AVALIAÇÃO SENSORIAL DE IOGURTE ADICIONADO DE “CAVIAR” DE CENOURA POR CRIANÇAS
}

\section{Development and sensory evaluation of yogurt added of "caviar" of carrot by children}

\author{
Richtier Gonçalves da Cruz ${ }^{1}$, Henrique Silvano Arruda², Virgínia Souza Santos ${ }^{3}$, \\ Martha Elisa Ferreira de Almeida ${ }^{3 *}$
}

\begin{abstract}
RESUMO
O objetivo do trabalho foi elaborar um iogurte com a adição de "caviar" de cenoura e analisar sua aceitação sensorial por crianças do ensino fundamental. $\mathrm{O}$ “caviar" foi elaborado utilizando-se a técnica da esferificação com alginato de sódio, sendo adicionado em iogurte do tipo batido sem a adição de polpa na proporção de uma porção de cenoura para uma porção de iogurte. Foram realizadas as análises microbiológicas e posteriormente a avaliação da aceitação sensorial com crianças. De acordo com as análises microbiológicas o produto estava apto para o consumo. O escore médio em pontos obtido na análise sensorial realizada com 52 crianças foi de 6,7 (sendo 6,6 no gênero masculino e 6,8 no feminino). As crianças do gênero feminino apresentaram as maiores notas $(\mathrm{p}<0,05)$. O índice de aceitabilidade geral obtido para o iogurte com "caviar" de cenoura foi de $95,70 \%$. Conclui-se que o iogurte acrescido de "caviar" de cenoura foi aceito sensorialmente, pois apresenta elevadas notas que reflete no seu índice de aceitabilidade, sugerindo que este produto seja empregado como uma alternativa para aumentar o consumo de cenoura por crianças.

Palavras-chave: gastronomia molecular; laticínios; leite fermentado; Daucus carota $\mathrm{L}$.
\end{abstract}

1 Escola Superior de Agricultura “Luiz de Queiroz”, Universidade de São Paulo (ESALQ - USP), Piracicaba, SP, Brasil.

2 Universidade Estadual de Campinas (UNICAMP), Campinas, SP, Brasil.

3 Universidade Federal de Viçosa (UFV), Campus de Rio Paranaíba, Caixa Postal 22, 38810-000, Rio Paranaíba, MG, Brasil. E-mail: martha.almeida@ufv.br

* Autor para correspondência.

Recebido / Received: 21/01/2015

Aprovado / Approved: 08/09/2015 


\begin{abstract}
This study aimed investigated to the preparation of yogurt with addition of "caviar" carrot and realize carried out sensory analysis of acceptance by children from elementary school. The "caviar" was prepared using the spherification technique with sodium alginate and added to the beaten-type yogurt without pulp addition at the ratio of one portion of the carrot for one portion of yogurt. Were conducted microbiological analyses and subsequently the sensory evaluation with children. The microbiological analyses showed that the product was fit for consumption. The average score in points obtained in the sensory analysis with 52 children was 6.7 (with 6.6 in males and 6.8 in females), it is that girls had higher scores $(\mathrm{p}<0.05)$. The general index of acceptability to yogurt with "caviar" of carrot was $95.70 \%$. It concludes that yogurt plus "caviar" carrot sensory was accepted because it presents high notes reflecting on their acceptability index, suggesting that this product is used as an alternative to increase the consumption of carrots by children.
\end{abstract}

Keywords: molecular gastronomy; dairy products; fermented milk; Daucus carota L.

\section{INTRODUÇ̃̃O}

A ciência de alimentos anteriormente se preocupava em desenvolver alimentos para a sobrevivência humana, objetivo este que foi substituído pelo conceito de produzi-los com qualidade. Isto ocorreu, pois, além de serem utilizados como veículo de promoção do bem estar e saúde, os alimentos passaram a ser vistos como redutores dos riscos de algumas doenças, o que tem incentivado as pesquisas de componentes naturais e o desenvolvimento de novos ingredientes que possibilitam a inovação no setor alimentício (MATSUBARA, 2001).

Dentre as hortaliças, a cenoura (Daucus carota L.) se destaca por ser um alimento com elevados teores de carotenoides (pró-vitamina A), vitaminas B1 e B2 e sais minerais como o potássio, o cálcio e o fósforo (LUENGO et al., 2000).

O consumo desta hortaliça traz vários benefícios à saúde como a prevenção da carcinogênese cervical por indução da apoptose de células malignas e da cegueira noturna, bom desenvolvimento fetal, aumento da imunidade do organismo e diminuição no risco de desenvolvimento do diabetes mellitus (COSTA; ROSA, 2010). No entanto, o consumo de hortaliças no Brasil representa menos da metade das recomendações diárias para este tipo de alimento, e este fato se agrava ainda mais em famílias de baixa renda (GIUGLIANO; CARNEIRO, 2004). Outro fator que também diminui o consumo de hortaliças é que tais alimentos não são apreciados sensorialmente, principalmente pelo público infantil, e tendem a ser ingeridos em quantidades insuficientes.

O iogurte é um produto fermentado elaborado com leite usando uma cultura mista de Lactobacillus delbrueckii ssp. bulgaricus e Streptococcus thermophilus (PENNA et al., 1997). Este produto tem alcançado uma considerável importância econômica nos últimos anos, devido a sua composição nutricional, cuja imagem positiva como fonte de cálcio, vitaminas e proteínas pode aumentar ainda mais com a adição de outros compostos bioativos (GIUGGISBERG et al., 2007).

O consumo mundial de iogurte destacou-se na década de 1960 devido à adição de polpa de frutas para a atenuação do sabor ácido, resultando em uma maior aceitação 
popular do produto (ROCHA et al., 2008), bem como a diversificação na sua linha de produção, incluindo os iogurtes com teor reduzido de gordura ou probióticos, mousses de iogurte e sorvetes de iogurte (STAFFOLO et al., 2004).

Segundo dados da Pesquisa de Orçamentos Familiares (POF 2008-2009), entre 1974 e 2003, o iogurte apresentou um aumento de 702\% no seu consumo. Em 20082009 o consumo médio foi de $2,28 \mathrm{~kg}$, sendo maior na região Sul $(2,73 \mathrm{~kg})$, seguido pelas regiões Sudeste $(2,39 \mathrm{~kg})$, Centro-Oeste $(2,28 \mathrm{~kg})$, Nordeste $(1,95 \mathrm{~kg})$ e Norte $(1,79 \mathrm{~kg})$ (BRASIL, 2009). Assim, um incremento do consumo deste produto pode ser promovido com o emprego de técnicas que melhoram as características sensoriais, de forma que atenda às expectativas do consumidor com relação ao preço e ao valor nutricional.

Uma pesquisa realizada com 802 mães revelou que $49 \%$ delas se diziam influenciada pelos seus filhos nos supermercados, e que o produto mais desejado pelas crianças era o iogurte com $76 \%$ de aprovação, em segundo lugar estavam os salgadinhos com $71 \%$, e as balas e chocolates em terceiro, com $70 \%$ (RÉVILLION; KLAFKE, 2004).

Criada em 1988, pelo físico Húngaro Nicholas Kurti e o químico francês Hervé This, a gastronomia molecular estuda os alimentos a partir de conceitos da física, química, biologia e neurologia, extraindo conhecimentos que se aplicam ao desenvolvimento de novos produtos. Posteriormente, a gastronomia molecular deu origem à cozinha molecular que compreende a utilização prática dos conceitos estudados na gastronomia (MIRALBUENO, 2009).

A esferificação foi criada por Ferran Adriá (E1 Bulli) em 2003, e depois se tornou umas das técnicas mais difundidas na cozinha molecular. Ela consiste em aprisionar um líquido numa esfera que é preparada com um gel constituído de alginato de cálcio. $\mathrm{O}$ suco de algum alimento contendo alginato de sódio é gotejado em uma solução com cloreto de cálcio. Através desta técnica é possível produzir esferas com textura e aparência similares ao caviar (GASTRONOMYLAB, 2015). O alginato de sódio reage com o cálcio levando a formação de uma película em forma de gel (alginato de cálcio) que reveste as esferas resultantes da esferificação, sendo este fenômeno também denominado de gelificação iônica, que apresenta a vantagem de possuir um baixo custo, além de ser uma reação rápida (FENNEMA, 1996).

A técnica da gastronomia molecular, envolvendo a esferificação, tem sido utilizada para o preparo de alimentos mais nutritivos (REILLY rt. al., 2013). O desenvolvimento do iogurte com "caviar" de cenoura pode aumentar o valor nutricional da bebida, pois esta hortaliça é muito cultivada no município de Rio Paranaíba (MG), e possui elevado valor nutricional, uma vez que ela é rica em carotenoides. Assim, este trabalho teve como objetivo elaborar um iogurte com a adição de "caviar" de cenoura e analisar sua aceitação sensorial por crianças.

\section{MATERIAL E MÉTODOS}

Para o preparo do "caviar", as cenouras foram adquiridas no comércio local de Rio Paranaíba (MG), e processadas no Laboratório de Alimentos do Centro Vocacional Tecnológico (CVT) desta cidade. Em seguida, foram lavadas em água corrente, sanitizadas com água clorada (100 ppm de hipoclorito de sódio CRT) por 10 minutos e descascadas. As hortaliças foram trituradas em multiprocessador por 4 minutos, e posteriormente foram prensadas manualmente para a extração do suco que foi filtrado em papel filtro. Em seguida, adicionou-se $1,0 \%(\mathrm{~m} / \mathrm{v})$ de alginato de sódio ao suco de cenoura, sendo este homogeneizado em liquidificador por 1 minuto em velocidade média, para se obter uma solução uniforme. O suco de cenoura contendo alginato de sódio foi 
gotejado com o auxílio de um conta-gotas descartável de plástico, em uma solução de $0,5 \%(\mathrm{~m} / \mathrm{v})$ de cloreto de cálcio, no qual as esferas permaneceram por 1 minuto. Após a gelificação, as esferas "caviar” foram lavadas em água corrente a temperatura ambiente por 30 segundos, para a retirada do excesso de cloreto de cálcio.

Foram realizadas análises físico-químicas no suco de cenoura para determinar o $\mathrm{pH}$, pelo método de potenciometria direta (pHmetro digital com eletrodo de vidro combinado) (INSTITUTO ADOLFO LUTZ, 1985), e também o teor de sólidos solúveis (Brix) medido diretamente em refratômetro (AOAC, 1984).

\section{Elaboração do iogurte com o "caviar"}

Os ingredientes e suas respectivas quantidades utilizadas no leite integral para produção do iogurte com o "caviar" de cenoura estão apresentados na Tabela 1 .

Tabela 1 - Ingredientes e quantidade utilizados na elaboração do iogurte com o "caviar" de cenoura

\begin{tabular}{lc}
\hline \multicolumn{1}{c}{ Ingredientes } & Quantidades (\%) \\
\hline "Caviar" de cenoura & 12,10 \\
Sacarose & 10,00 \\
Leite em pó desnatado & 4,00 \\
Cultura de iogurte - DVS & 0,001 \\
\hline
\end{tabular}

De acordo com Philippi (2013), uma porção de cenoura tem $36 \mathrm{~g}$ e a de iogurte possui 140 g. A quantidade de "caviar" adicionado ao iogurte foi na proporção de uma porção de cenoura para uma de iogurte (1:1). Para analisar o peso que uma porção de cenoura representaria no caviar pronto, extraiu-se, em triplicata, o suco de uma porção de cenoura (36 g) e realizou-se o processo de esferificação para a produção do "caviar".
A média do peso obtido foi utilizada como referência para a quantidade de "caviar" que representava uma porção de cenoura a ser adicionada em uma porção de iogurte.

O leite integral foi fermentado com a cultura de Lactobacillus delbrueckii ssp. bulgaricus e Streptococcus thermophilus (1:1) (Christian Hansen $^{\circledR}$ ) na proporção de $0,001 \%$, e mantido a temperatura de $45{ }^{\circ} \mathrm{C}$ até o $\mathrm{pH}$ de 3,8 e acidez titulável de 0,83 ( $\%$ de ácido lático), sendo resfriado a $10{ }^{\circ} \mathrm{C}$ e adicionado do "caviar" de cenoura no momento da quebra para a obtenção de iogurte do tipo batido. Em seguida, o iogurte foi envasado manualmente em embalagens de polietileno e armazenado em câmara fria sob refrigeração até o momento das análises de acidez titulável e $\mathrm{pH}$, que foram feitas depois da adição do "caviar" ao iogurte (INSTITUTO ADOLFO LUTZ, 1985). O fluxograma de produção do iogurte está demonstrado na Figura 1, conforme descrito por Ferreira (2005).

\section{Análises microbiológicas}

Para verificar se as amostras estavam aptas para o consumo humano foram realizadas análises de coliformes a $30{ }^{\circ} \mathrm{C}$, bolores e leveduras (BRASIL, 2007).

Após a sanitização das mãos e das embalagens do iogurte com álcool 70\%, foram retirados assepticamente $25 \mathrm{~mL}$ de cada amostra, os quais foram diluídos em $225 \mathrm{~mL}$ de solução salina peptonada $(0,1 \%)$ originando a diluição $10^{-1}$, sendo em seguida realizadas as diluições $10^{-2}$ e $10^{-3}$ para a análise dos coliformes.

Realizou-se o teste presuntivo que constitui na adição de $1 \mathrm{~mL}$ de cada diluição em três séries de tubos contendo $10 \mathrm{~mL}$ do meio LST (lauril sulfato de sódio) e um tubo de Durhan invertido. Eles foram incubados a $35-37{ }^{\circ} \mathrm{C}$ por $24-48$ horas, sendo considerados positivos os tubos de Durhan que apresentaram gás (resultado da fermentação da lactose) no seu interior. Retirou-se uma 


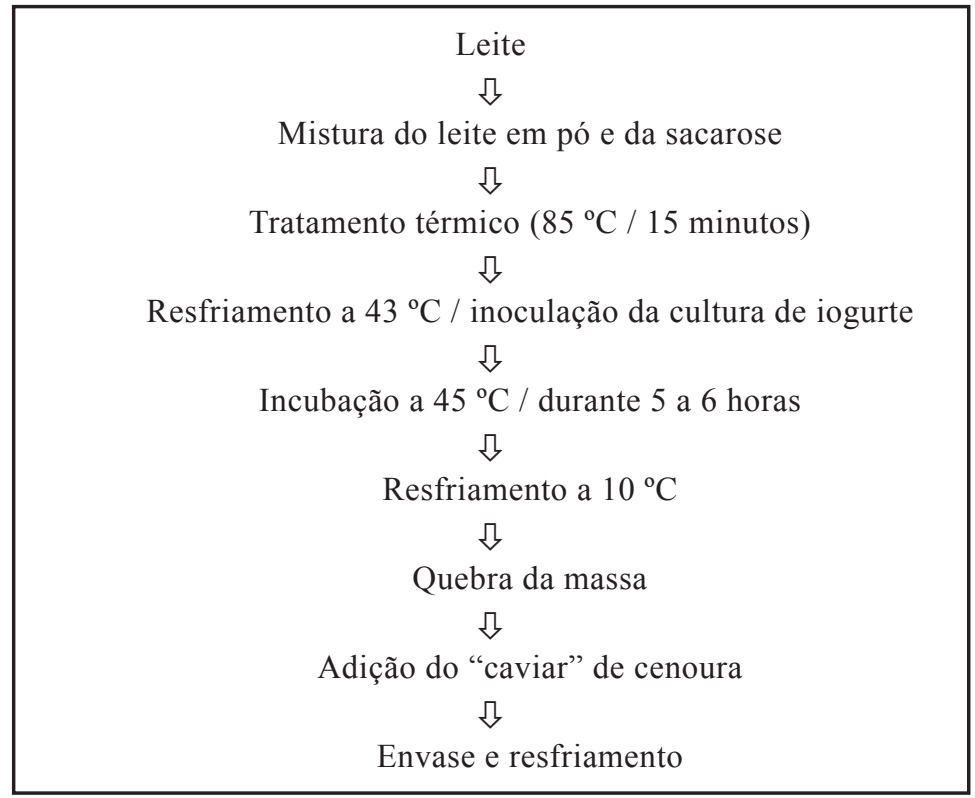

Figura 1 - Fluxograma de produção do iogurte do tipo batido com a adição de "caviar" de cenoura

alíquota de cada tubo positivo de LST para a realização do teste confirmativo, e inoculou-se nos tubos de $10 \mathrm{~mL}$ de caldo verde brilhante bile lactose (VBBL) o tubo de Durhan invertido para confirmar a presença de coliformes totais, incubando-se em estufa a $30-35^{\circ} \mathrm{C}$ por $24-48$ horas. A confirmação de presença de coliformes totais é evidenciada pelo comportamento das bactérias que, ao se multiplicarem, fermentam a lactose produzindo gás, que fica aprisionado no interior do tubo de Durhan, considerando um resultado positivo.

A interpretação foi realizada a partir dos tubos positivos, com base na comparação com os resultados descritos na tabela do Número Mais Provável (NMP) para obter o número de coliformes presentes na amostra.

Para a análise de bolores e leveduras pesou-se $25 \mathrm{~g}$ da amostra, adicionou-se $225 \mathrm{~mL}$ de solução salina peptonada $(0,1 \%)$ e inoculou-se $0,1 \mathrm{~mL}$ da diluição selecionada sobre a superfície seca de ágar batata glicose
(2\%) acidificada ao $\mathrm{pH}$ de 3,5. Com o auxílio da alça Drigalski, espalhou-se o inócuo por toda a superfície do meio, até sua completa absorção. Incubou-se as placas a $25^{\circ} \mathrm{C}$, por 5 a 7 dias, e fez-se a contagem naquelas que possuíam de 15 a 150 colônias.

\section{Aceitação sensorial}

A aceitação sensorial foi realizada após o resultado da análise microbiológica do iogurte com o "caviar" (48 horas depois de sua produção), com crianças do ensino fundamental do município de Rio Paranaíba (MG).

Para avaliar o iogurte adicionado do "caviar" foi realizado um teste de aceitação utilizando a escala hedônica facial de sete pontos de acordo com Reis; Minim (2010), na qual cada número representava um termo hedônico, sendo: 1 = desgostei extremamente, 2 = desgostei muito, 3 = desgostei, $4=$ indiferente, 5 = gostei, $6=$ gostei muito e 7 = gostei extremamente. Foi calculado o 
índice de aceitabilidade segundo Teixeira et al. (1987).

Durante a análise da aceitação sensorial, as crianças foram orientadas sobre o preenchimento correto da ficha de avaliação. Cada participante recebeu uma amostra contendo $20 \mathrm{~mL}$ de iogurte e $2,8 \mathrm{~g}$ de "caviar" (Figura 2). Tal procedimento fez-se necessário para que todos os provadores recebessem a mesma quantidade de "caviar" na porção de iogurte. Cada criança foi questionada sobre o nome do alimento que era feito o caviar.

O estudo foi realizado após a aprovação do Comitê de Ética em Pesquisa da Universidade Federal de Viçosa, protocolo no 478.951 .

\section{Análise estatística}

Os dados obtidos no teste de aceitação foram submetidos ao teste $\mathrm{t}$ para amostras independentes, a 5\% de probabilidade, no programa Statistical Package for the Social Sciences (SPSS), versão 20.0.

\section{RESULTADOS E DISCUSSÃO}

A análise de uma porção de cenoura crua (36 g) resultou numa média de $17 \mathrm{~g}$ de

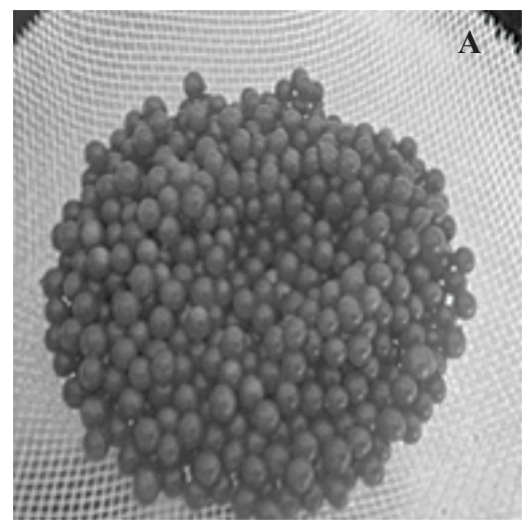

"caviar" para $140 \mathrm{~g}$ de iogurte, representando $12,1 \%$ no produto final.

O suco de cenoura utilizado no preparo do caviar apresentou um teor de sólidos solúveis de $6,1^{\circ}$ Brix e pH de 5,9. O iogurte não apresentou gás na análise do Número Mais Provável e nem bolores e leveduras, estando apto para o consumo humano de acordo com a Instrução Normativa $n^{\circ} 46$ de 23 de outubro de 2007 (BRASIL, 2007). A adição do "caviar" de cenoura não alterou o pH nem a acidez do iogurte.

Mediante o resultado negativo para a presença de coliformes a $30{ }^{\circ} \mathrm{C}$, não se fizeram necessárias às etapas seguintes de coliformes a $45{ }^{\circ} \mathrm{C}$ e termotolerantes. Estes resultados são indicativos de boas condições higiênico-sanitárias, durante o processo de elaboração do iogurte não apresentando uma pós-contaminação.

Participaram da análise sensorial 52 crianças, sendo 25 do gênero masculino e 27 do feminino, na faixa etária de 7 a 9 anos, 11 meses e 30 dias, estudantes do ensino fundamental da Escola Estadual Professor José Luiz de Araújo, do município de Rio Paranaíba (MG).

O escore médio em nota do produto foi de 6,7 estando classificado entre os termos

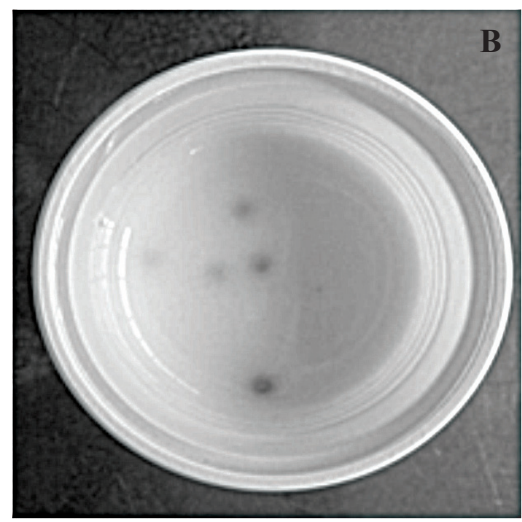

Figura 2 - A) “Caviar” de cenoura elaborado para a adição ao iogurte. B) Amostra para aceitação sensorial do iogurte com “caviar” de cenoura. Rio Paranaíba, MG, 2014. 
"gostei muito" e "gostei extremamente". Segundo Lima et al. (2011), a produção mundial e a ingestão de iogurtes cresceram durante os últimos anos, principalmente com a introdução dos aromas de frutas, sendo observado que houve uma queda no consumo de leite, enquanto as bebidas industrializadas se tornaram as favoritas das crianças. $\mathrm{O}$ consumo adequado de iogurte pelas crianças tem um impacto positivo em sua alimentação, uma vez que melhora o fornecimento de cálcio e de outros nutrientes como as proteínas e vitaminas (NESTAL, 1993).

Quanto à aceitação do produto para os gêneros masculino e feminino, as médias totais obtidas foram de 6,60 e 6,80; respectivamente, sendo que as meninas atribuíram maiores notas para o produto $(\mathrm{p}<0,05)$. Para ambos os gêneros, as notas da amostra permitiram classificá-la nos termos hedônicos "gostei muito" e "gostei extremamente". Na Tabela 2 estão dispostos os escores médios atribuídos pelo gênero e a idade das crianças.

Tabela 2 - Aceitação sensorial do iogurte com "caviar" segundo o gênero e a idade

\begin{tabular}{ccc}
\hline Idade & \multicolumn{2}{c}{ Gênero } \\
\cline { 2 - 3 }$($ anos $)$ & Masculino & Feminino \\
\hline 7 & $6,60 \pm 0,40^{*}$ & $6,80 \pm 0,35^{*}$ \\
8 & $6,50 \pm 0,79^{*}$ & $6,90 \pm 0,34^{*}$ \\
9 & $6,80 \pm 0,83^{\text {ns }}$ & $6,70 \pm 0,65^{\text {ns }}$ \\
\hline Total & $6,60 \pm 0,48^{*}$ & $6,80 \pm 0,81^{*}$ \\
\hline
\end{tabular}

*significativo na linha pelo teste $\mathrm{t}$ para amostras independentes, a $5 \%$ de probabilidade. ns $=$ não significativo pelo teste $\mathrm{t}$ para amostras independentes. Os valores são apresentados como média e desvio padrão.

As meninas de 7 e 8 anos atribuíram maiores notas para o iogurte adicionado de caviar de cenoura $(\mathrm{p}<0,05)$, quando comparadas aos meninos da mesma idade. Segundo Krolow (2008), o iogurte é um produto identificado com o público infantil, provavelmente devido à conotação dada pela mídia que o direciona para este segmento. Mas, independente da condição socioeconômica, ele é um alimento "democrático" que é consumido por qualquer público, inclusive os adultos e idosos.

Rocha et al. (2004) obtiveram médias correspondentes a "indiferente" e "gostei" na análise sensorial por crianças e adolescentes de 9 e 10 anos dos iogurtes de araticum, cagaita e mangaba elaborados com leite de búfala, enquanto Borges et al. (2009), alcançaram escores entre 6,00 e 7,00; equivalentes a "gostei ligeiramente"e "gostei regularmente" para o iogurte sabor cajá, em uma avaliação realizada com adolescentes de 11 a 16 anos.

Neste estudo, o índice de aceitabilidade geral obtido para o iogurte com "caviar" de cenoura foi de $95,7 \%$, refletindo uma elevada aceitação sensorial do produto. Segundo Frutuoso et al. (2012), para que um produto seja aceito pelo público, é necessário que ele tenha no mínimo um índice de aceitabilidade de $70 \%$ de aprovação, sendo destacado por Dutcosky (2007), que valores iguais ou superiores a $70 \%$ indicam a possibilidade de o produto ser aceito satisfatoriamente quando elaborado em uma escala comercial.

As esferas não apresentaram um sabor identificável de cenoura, uma vez que nenhuma criança conseguiu acertar o nome do alimento a partir do qual foi elaborado o "caviar". Sugere-se que este seja um ponto positivo na alimentação infantil, que geralmente apresenta resistência sensorial quanto ao consumo de cenoura. Desta forma, as crianças poderão consumir o produto e usufruir dos nutrientes presentes nesta hortaliça, uma vez que o suco usado para o preparo do "caviar" não foi submetido a nenhum tipo de tratamento térmico que pudesse diminuir a quantidade de nutrientes, como acontece no procedimento de cocção.

Por tratar-se de um produto novo, e que as crianças não conseguiram identificar 
o sabor do "caviar", tal fato poderá gerar inicialmente uma menor aceitação, pois um sabor desconhecido ou não identificado para o público infantil tende a resultar no comportamento descrito como neofobia alimentar, que se caracteriza pela resistência à inovação, mas que não significa que o alimento será rejeitado continuamente. Segundo Jomori et al. (2008), esta atitude pode ser revertida caso o produto seja oferecido em outras oportunidades. Contudo, apesar das crianças não identificarem o sabor da cenoura no "caviar", isto não acarretou uma menor aceitação do produto, mediante o índice de aceitabilidade obtido.

\section{CONCLUSÕES}

O iogurte acrescido de "caviar" de cenoura apresenta um elevado índice de aceitabilidade, independente da idade e do gênero das crianças avaliadas, sendo que as meninas de 7 e 8 anos atribuíram maiores notas para o alimento teste.

Sugere-se que este produto elaborado seja uma alternativa para aumentar o consumo de cenoura por crianças, estimulando hábitos alimentares mais saudáveis.

\section{AGRADECIMENTOS}

A todas as crianças da Escola Estadual Professor José Luiz de Araújo, do município de Rio Paranaíba (MG) que participaram do teste sensorial, e àqueles que contribuíram para a realização do estudo.

\section{REFERÊNCIAS}

ASSOCIATION OF OFFICIAL ANALYTICAL CHEMISTS (AOAC). Official Methods of Analysis. 14. ed. Washington: DC, 1984. 1094 p.

BOrGES, K. C.; MEDEIROS, A. C. L.; CORREIA, R. T. P. Iogurte de leite de búfala sabor cajá (Spondias lutea L.): caracterização físico-química e aceitação sensorial entre indivíduos de 11 a 16 anos. Alimentos e Nutrição, v. 20, n. 2, p. 295-300, 2009.

BRASIL. Ministério da Agricultura, Pecuária e Abastecimento. Instrução Normativa $n^{-} 46$ de 23 de outubro de 2007. Regulamento Técnico de Identidade e Qualidade de Leites Fermentados. Diário Oficial da República Federativa do Brasil, Brasília, 24 out. 2007. Seção 1.

BRASIL. Pesquisa de Orçamentos Familiares - POF 2008-2009. Aquisição alimentar domiciliar per capita - Brasil e Grandes Regiões. Disponível em: <http://www. ibge.gov.br/home/estatistica/populacao/ condicaodevida/pof/2008_2009_aquisicao/ pof20082009_aquisicao.pdf>. Acesso em: 20 jan. 2015.

COSTA, N. M. B.; ROSA, C. O. B. Alimentos Funcionais: Componentes Bioativos e Efeitos Fisiológicos. Rio de Janeiro: Rubio, 2010. 560 p.

DUTCOSKY, S. D. Análise Sensorial de Alimentos. 2. ed. Curitiba: Champagnat, 2007. 239 p.

FENNEMA, O. Food Chemistry. 3. ed. New York: Marcel Dekker, 1996. 1088 p.

FERREIRA, C. L. L. F. Produtos Lácteos Fermentados: Aspectos Bioquímicos e Tecnológicos. 3. ed. Viçosa: UFV, 2005. 112 p.

FRUTUOSO, A. E.; ANDRADE, P. L.; PEREIRA, J. O. P. Inovação no desenvolvimento de bebida láctea fermentada com leite de vaca e soro de queijo de cabra. Revista do Instituto de Laticínios Cândido Tostes, v. 67, n. 386, p. 29-37, 2012.

GASTRONOMYLAB. Gastronomia molecular. Disponível em: <http://gastronomylab. 
com/index.php/extensions/gastronomiamolecular>. Acesso em: 20 jan. 2015.

GIUGLIANO, R.; CARNEIRO, E. C. Fatores associados a obesidade em escolares. Jornal de Pediatria, v. 80, n. 1, p. 17-22, 2004.

GUGGISBERG, D.; EBERHARD, P.; ALBRECH, B. Rheological characterization of set yoghurt produced whit additivies of native whey proteins. International Dairy Journal, v. 17, n. 11, p. 1353-1359, 2007.

INSTITUTO ADOLFO LUTZ. Métodos Químicos e Físicos para Análise de Alimentos. 3. ed. São Paulo: IMESP, 1985. v. 1, 533 p.

JOMORI, M. M.; PROENÇA, R. P. C.; CALVO, M. C. M. Determinantes de escolha alimentar. Revista de Nutrição, v. 21, n. 1, p. 63-73, 2008.

KROLOW, A. C. R. Iogurte integral sabor café. Pelotas: Embrapa Clima Temperado, 2008. 4 p. (Comunicado Técnico, 193).

LIMA, H. M. R.; LIMA, L. R.; GALVÃO, F. F. S. P. Consumo infantil de bebidas lácteas: sólidos solúveis totais (Brix) e pH. Revista Odontologia Clínico Científica, v. 10, n. 3, p. 237-241, 2011.

LUEnGO, R. F. A. et al. Tabela de Composição Nutricional das Hortaliças. Brasília: Embrapa Hortaliças, 2000. 4 p.

MATSUBARA, S. Alimentos funcionais: uma tendência que abre perspectivas aos laticínios. Revista Indústria de Laticínios, v. 6, n. 34, p. 10-18, 2001.

MIRALBUENO, I. E. S. De la tradición a la innovación. 2009. Disponível em: <https:// cienviva.files.wordpress.com/2014/12/ folleto a5 viii jornadasb.pdf $>$. Acesso em: 20 jan. 2015.

NESTAL, P. Fortificación de los Alimentos en los Países en Desarrollo. Washington
(DC): Agencia de los Estados Unidos para el Desarrollo Internacional, 1993. 52 p.

PENNA, A. L. B.; OLIVEIRA, M.; BARUFFALDI, R. Análise de consistência de iogurte: correlação entre medida sensorial e instrumental. Ciência e Tecnologia de Alimentos, v. 17, n. 2, p. 98-101, 1997.

PHILIPPI, S. T. Tabela de Composição de Alimentos. Suporte para Decisão Nutricional. 4. ed. São Paulo: Manole, 2013.

REIS, R. C.; MINIM, V. P. R. Teste de aceitação. In: MINIM, V. P. R. Análise Sensorial: Estudos com Consumidores. 2. ed. Viçosa: UFV, 2010. cap. 3, p. 66-82.

REILLY, R.; FRANKEL, F. ; EDESSTEIN, S. Molecular gastronomy: transforming diets for dysphagia. Journal of Nutritional Healt \& Food Science, v. 1, n. 1, p. 1-6, 2013.

RÉVILliON, A. S. P.; KLAFKE, R. Os pequenos ditadores do consumo: a influência da criança nas decisões de compra familiares. 2004. In: CONGRESSO BRASILEIRO DE CIÊNCIAS DA COMUNICAÇÃO, 27., 2004. Porto Alegre. Anais... São Paulo: Intercom, 2004. CD-ROM.

ROCHA C. et al. Elaboração e avaliação de iogurte sabor frutos do cerrado. Boletim do Centro de Pesquisa de Processamento de Alimentos, v. 26, n. 2, p. 255-266, 2008.

ROCHA, C. et al. Iogurte de leite de búfala sabor frutos do cerrado. Boletim do Centro de Pesquisa de Processamento de Alimentos, v. 22, n. 21, p. 97-106, 2004.

STAFFOLO, M. et al. Influence of dietary fiber addition on sensory and rheological properties of yogurt. International Dairy Journal, v. 14, n. 3, p. 263-268, 2004.

TEIXEIRA，E.; MEINERT，E. M.; BARBETTA, P. A. Análise Sensorial de Alimentos. Florianópolis: UFSC, 1987. 182 p. 